\title{
RESEARCH INTO THE TEXTILE-BASED SIGNAL LINES MADE USING ULTRASONIC WELDING TECHNOLOGY
}

\author{
Jacek Leśnikowski* \\ Lodz University of Technology, Department of Architecture of Textiles, Łódź, Żeromskiego 116, 90-924, Poland \\ *Corresponding author. E-mail: lesnik@p.lodz.pl
}

\begin{abstract}
:
The article describes research into the transmission properties of textile signal lines (TSLs) made using ultrasonic welding technology. The presented TSLs are made from electroconductive, nickel coated, fabric strips welded between non-conducting textile layers. The article presents an analysis of the usability of the ultrasonic welding method for creating TSLs. This analysis shows that direct welding of an electroconductive path with the substrate increases its linear resistance, making it impossible to create a properly functioning line. This article presents an alternative method of creating the line using ultrasound welding technology.
\end{abstract}

\section{Keywords:}

Textile signal line, textile transmission line, smart clothing, textronics, E-textiles, ultrasonic welding, wearable

\section{Introduction}

The development of the textile signal lines (TSLs) is an important part of the creation of e-textiles. The term "e-textiles" refers to a broad field of products and studies that extend the functionality and usefulness of common textiles. An example of the e-textile is clothing with the implementation of electronic systems. In this type of product, electronic modules are usually placed in different places. Using conventional signal lines in the form of copper wires for connecting these modules have many disadvantages, particularly the high rigidity of the lines and clothing in which they are applied. Therefore, TSLs due to their flexibility are a modern alternative to conventional lines.

There are many examples of the use of TSLs in e-textiles. One of them is TSL connecting elements of electronic systems for monitoring human physiological parameters [1-3]. An example of such an application may be a line transmitting signal from various types of sensors, for example, capacitive sweat sensors [4]. Another potential application is TSL for powering textile antennas [5-7].

Owing to the wide array of potential applications, the TSLs are subject to extensive research worldwide. Currently, weaving and knitting [8], printing [9-11], sewing [12], and embroidery $[13,14]$ technologies can be used to produce TSLs. Some researchers propose rather expensive techniques like magnetron sputtering [15].

In the weaving or knitting method [8], some yarns of the knitted (weaved) textile are replaced with electroconductive filaments. These filaments can be in the form of metallic wires or electroconductive textile threads. In the printing method, the electroconductive paths are printed on nonconductive flat textile using electroconductive ink.

In this method, the properties of the TSL depend mainly on the quality of the electroconductive ink. In the method proposed by Yongsang Kim et al [9] and Merritt [11], the silver-based conductive ink is painted through the open areas of a meshreinforced stencil onto the substrate fabric. The standard screen-printing process is comprised of printing, drying, and firing. It also needs the preparation of mesh-reinforced stencil. Therefore, this method is particularly useful in mass production, not for prototypes. Another possible printing method is inkjet printing but the development of cheap electroconductive ink for inkjet printing is still the subject of research.

The electroconductive paths of the line can also be embroidered with an electroconductive thread [13], [14]. Unfortunately, this method cannot be used to easily make TSLs with separated layers that differ in electrical conductivity. It is caused by the penetration of the electroconductive thread through the nonconductive textile layer forming the substrate of the line. In turn, the lines with separated layers (like microstrip, coplanar) are commonly used to transmit high-frequency signals.

An alternative method for the methods mentioned above is hot air welding technology described in [16]. In the proposed method, hot air sealing for obtaining textile transmission line was conducted using $100 \%$ PES-woven fabric, GoreTex® waterproof welding tape and electroconductive yarn. Results described in [16], based on conductivity and signal transference capabilities, are promising for the manufacturing of e-textile 
transmission lines through hot air welding technology. Although the authors report that the bending rigidities increased after the welding process.

An alternative to using hot air is to use ultrasound. An example of the TSL implementation using the ultrasonic method is presented in [17]. The electroconductive paths of the line presented in [17] were also made from electroconductive yarns. Bahadir et al [16] and Atalay et al. [17] present the results of measurements of the line parameters, which confirms only its usefulness for conducting a constant and low-frequency signal. Therefore, the research presented later in the article consists also of suitability for conducting a high-frequency analog signal or high-speed digital signal. The article presents constructed TSLs made from electroconductive, nickel-plated polyester strips of fabric welded on the nonconductive polyester fabric used as a substrate of the line. These fabrics were connected using ultrasonic welding technology. The TSLs presented in the article are designed for high-frequency applications. For lines transmitting high-frequency and digital signals, the dimensions of its electroconductive elements and distances between them are crucial for proper operation. For example, a deviation in the gap width between the signal path and ground path of a few tenths of a millimetre can cause a change in the characteristic impedance of the line by a few ohms. This may affect the quality of signal transmission. Making such a line from textile materials is a real challenge.

The following article analyzes the usability of the ultrasonic welding method for making TSLs from fabric.

\section{Materials and methods}

As part of the research work, two types of lines were made. The first type of TSL was designed in two-layered fabric constructions, as shown in Figure 1. The length of the lines was assumed as $150 \mathrm{~mm}$ while the width was assumed as $35 \mathrm{~mm}$.

The constructed TSL consists of fabric substrate (4), upper signal path (2) and two ground paths (3). The second version of the TSL made as part of the research was a line with additional, upper (1) and bottom (5) cover. The construction of the TSL shown in Figure 1 allows easily change the characteristic impedance of the line by changing the distance between ground

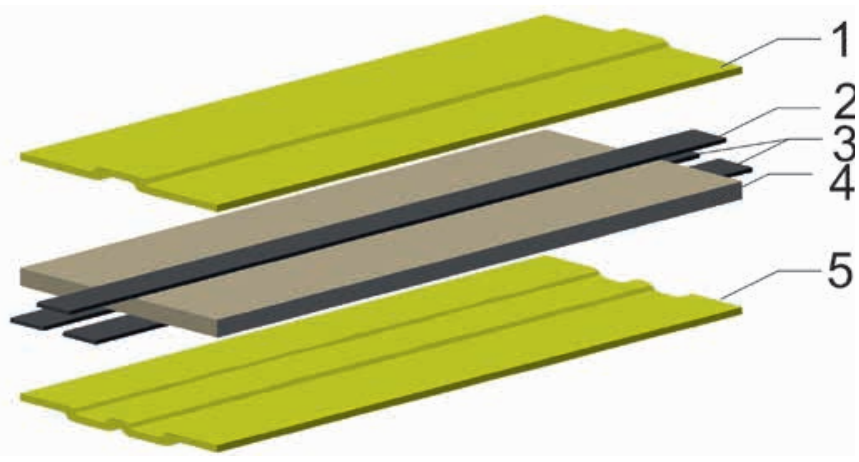

Figure 1. Expanded view of welded TSL with additional cover paths (3). In this line, the reduction of the distance between ground paths decreases the characteristic impedance of the line. More about the properties of this line can be found in [12].

The second kind of the constructed TSL is the textile coplanar line as shown in Figure 2. The coplanar TSL consists of fabric substrate (4), signal path (3), and two ground paths (3).

This line was also made in two variants: with and without additional, upper cover (1).

All signal paths were made from an electroconductive, nickelplated, polyester fabric named Ponge. The main parameters of this fabric are shown in Table 1. The selected fabric is characterized by high electrical conductivity. eElectroconductive paths of the lines are in the form of strips cut manually from electroconductive fabric. The width of the electroconductive signal paths in all tested lines was equal to $5 \mathrm{~mm}$, whereas the linear resistance of each electroconductive path was equal to $0,15 \mathrm{Ohm} / \mathrm{cm}$.

The main parameters of the polyester fabrics used as substrate are shown in Table 2. Fabrics that differ significantly in properties, such as thickness and surface mass, were chosen.

The PFAFF 8310 ultrasonic welding machine (Figure 3) was used to make all the lines presented in the article. The machine is equipped with $35 \mathrm{kHz}, 400 \mathrm{~W}$ ultrasonic generator and sonotrode with $5 \mathrm{~mm}$ width.

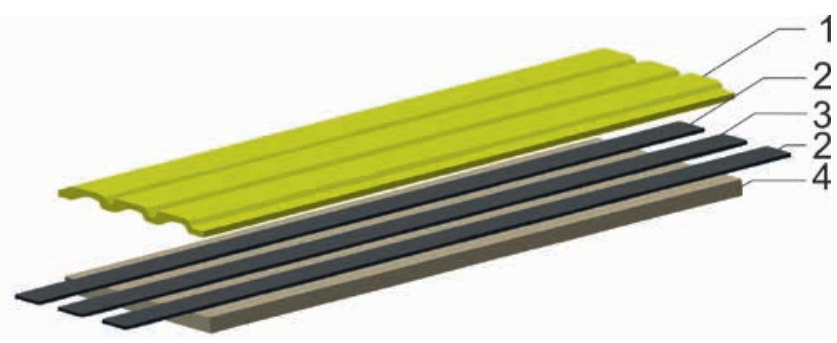

Figure 2. Expanded view of welded coplanar TSL with additional cover

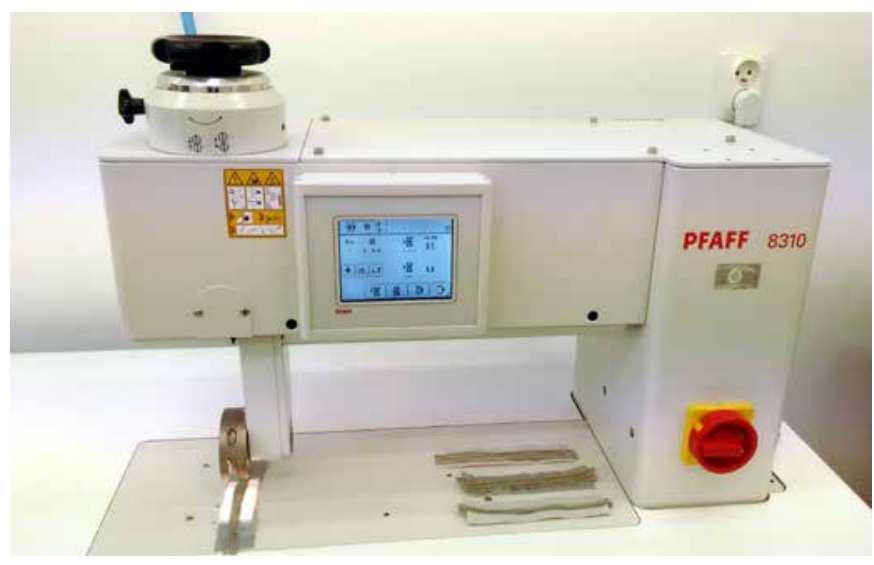

Figure 3. PFAFF 8310 ultrasonic welding machine 
Table 1. Basic parameters of metallized fabric used as electroconductive paths of the tested lines

\begin{tabular}{|c|c|c|c|c|c|c|c|}
\hline Material & Weave & Thickness & $\begin{array}{c}\text { Surface } \\
\text { resistivity }\end{array}$ & $\begin{array}{c}\text { Nickel } \\
\text { amount }\end{array}$ & $\begin{array}{c}\text { Surface } \\
\text { mass }\end{array}$ & $\begin{array}{c}\text { Warp } \\
\text { density }\end{array}$ & $\begin{array}{c}\text { Weft } \\
\text { density }\end{array}$ \\
\hline- & - & $\mathrm{mm}$ & Ohm/sq & $\mathrm{g} / \mathrm{m} 2$ & $\mathrm{~g} / \mathrm{m} 2$ & Yarns/cm & Yarns/cm \\
\hline $\begin{array}{c}\text { Nickel metallized } \\
\text { polyester }\end{array}$ & Plain & 0.15 & 0.4 & 16 & $60 \pm 15$ & 26 & 18 \\
\hline
\end{tabular}

Table 2. Example of selected polyester fabrics used as a substrate of the TSLs

\begin{tabular}{|c|c|c|c|c|c|}
\hline Symbol of fabric & Weave & Thickness & Surface mass & Warp yarn density & Weft yarn density \\
\hline & - & $\mathbf{m m}$ & $\mathbf{g} / \mathbf{m}^{\mathbf{2}}$ & threads/cm & threads/cm \\
\hline TK9 & Plain & 0,08 & 56 & 39 & 33 \\
\hline M13 & Satin & 0,48 & 160 & 82 & 30 \\
\hline M16 & Plain & 0,27 & 116 & 44 & 35 \\
\hline M18 & Panama & 0,67 & 219 & 49 & 40 \\
\hline
\end{tabular}

Table 3. Parameters used in the bonding strength test

\begin{tabular}{|c|c|c|c|}
\hline Test no & Power & Speed & Pressure \\
\hline- & $\%$ & $\mathrm{~m} / \mathrm{min}$ & Bar \\
\hline 1 & 100 & 0,5 & 4 \\
\hline 2 & 100 & 0,1 & 4 \\
\hline 3 & 100 & 0,5 & 1 \\
\hline 4 & 100 & 0,1 & 1 \\
\hline 5 & 50 & 0,5 & 4 \\
\hline 6 & 50 & 0,1 & 4 \\
\hline 7 & 50 & 0,5 & 1 \\
\hline 8 & 50 & 0,1 & 1 \\
\hline
\end{tabular}

\section{Measured parameters}

All measurements were carried out under standard testing climatic conditions at $20^{\circ} \mathrm{C}$ and $65 \%$ relative humidity.

At the beginning of the study, the electroconductive paths were welded directly to the fabric substrate. Next, the linear resistance of the welded electroconductive paths was measured.

For these tests, different parameters of the welding process were used. The sets of parameters used in the tests are shown in Table 3.

Resistance measurements were made using Agilent 34410A digital multimeter. Four electrode - four-wire method was used according to [18] standard. The tests were carried out for all fabrics shown in Table 2.

Next, the bonding strength between the electroconductive paths and the substrate was tested (Figure 4). Bonding strength measurements were made using an Instron strength testing machine with a constant test speed of $50 \mathrm{~mm} / \mathrm{min}$.

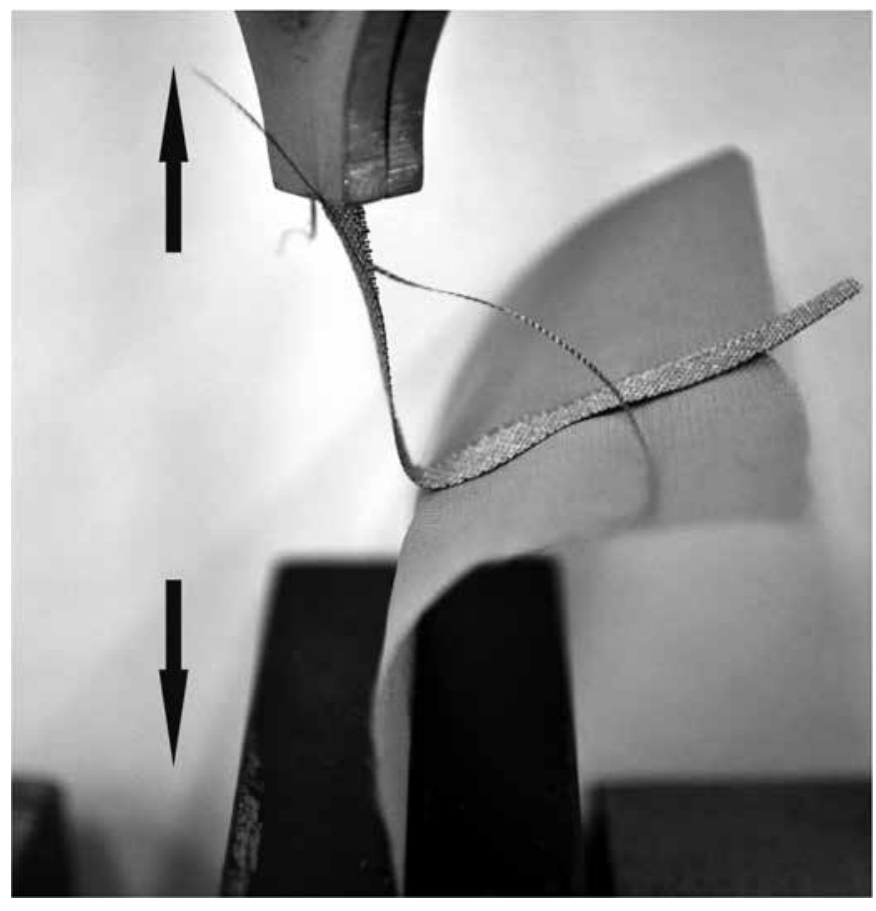

Figure 4. Bonding strength measurements using an Instron strength test machine.

In the first part of the electrical properties tests, the linear resistances characterizing the properties of the TSLs working as DC lines were measured. In the second part of the tests, signal integrity in TSLs transmitting high-frequency signals was checked.

Signal integrity in high-frequency TSLs is a complex problem. The quality of the line is characterized by many parameters, such as characteristic impedance [19], scattering parameters [20], crosstalk [21], and others.

In this article, measurements of the characteristic impedance and scattering parameters were described. The characteristic impedance of the line should remain constant along the entire signal path containing the transmitter, signal line, and a receiver. This assures a lack of reflections and distortion of the 


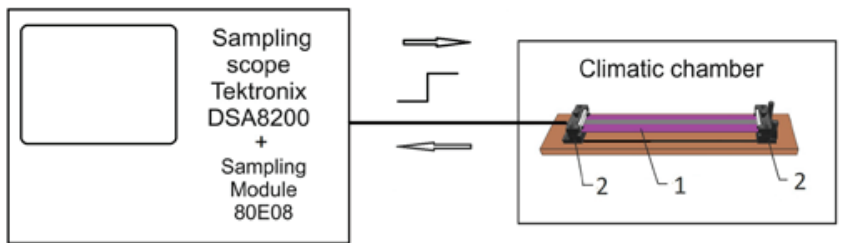

Figure 5. TDR test stand.

transmitted signal. To measure the characteristic impedance, Tektronix DSA 8200 sampling scope with 80E08 TDR sampling module was used (Figure 5). The tested TSL (1) is placed between two clamps (2) enabling the connection of its textile flat electroconductive paths to the measuring instruments as shown in Figure 5. In the TDR method, the transient response of transmission lines by injecting a step voltage waveform on the TSLs is measured. The voltage signal propagates with known velocity, along the line with typical reflections at points where impedance changes. This method allows for determining a so-called impedance profile. Such a profile represents the characteristic impedance of each point of the line as a function of its distance from the beginning of the line.

To measure the scattering parameters, Rhode\&Schwarz ZVA40 network analyzer was used. The same clamps as for the characteristic impedance measurements were used. The value of so-called $s_{11}$ scattering parameter is a measure of the amount of signal reflection from the TSL. When the amplitude of the $s_{11}$ is equal to $0 \mathrm{~dB}$, it means that the whole signal is reflected from the line. Another important scattering parameter is $s_{21}$ parameter. When the amplitude of the $s_{21}$ is equal to $0 \mathrm{~dB}$, it means that the whole signal is passed through the TSL. The ideal TSL should have $s_{11}=-\infty$ and $s_{21}=0$. More about the stands used to measure characteristic impedance and scattering parameters can be found in [19].

\section{Results and discussion}

The linear resistance of the electroconductive paths welded with different ultrasonic power is shown in Figure 6. The linear resistance of the electroconductive paths versus the quality of the weld is shown in Figure 7. The "very good" quality of the weld means that the bonding strength exceeds the breaking strength of the fibers of the electroconductive path. Separating them is not possible without destroying its fibers (Figure 8). Paths and substrate are permanently bonded with each other. The "correct" quality of the weld means that separating the electroconductive path and substrate is possible without destroying the electroconductive fibers. The "incorrect" quality of the weld means that the electroconductive path is not welded properly to the substrate and could be removed with practically no force. To obtain very good weld quality, high ultrasound power is needed regardless of welding speed and pressure. The use of less power than $100 \%$ of the maximum power results in a line susceptible to tearing the paths away from the substrate. Poor adhesion of electroconductive paths to the substrate is caused by their nickel coating necessary to give them electroconductivity. On the other hand, the use of high power causes an increase of the linear resistance

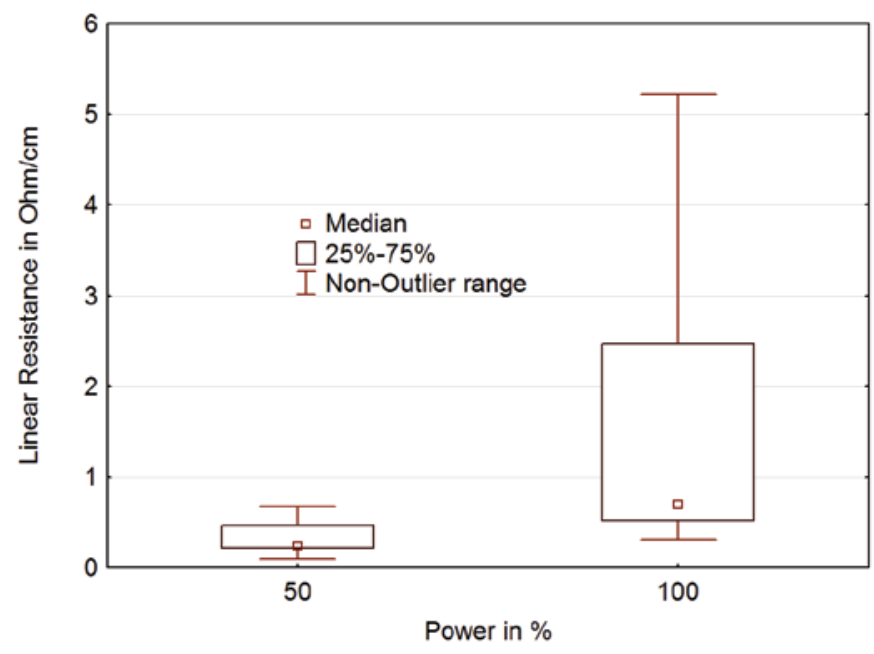

Figure 6. Linear resistance of electroconductive paths welded to substrate with different power.

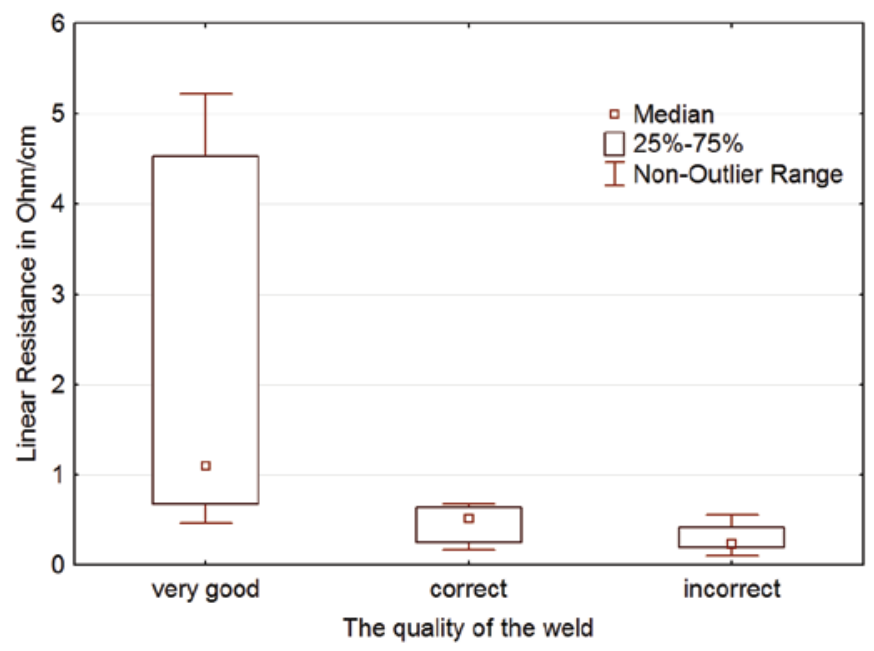

Figure 7. Linear resistance of the electroconductive paths versus quality of the weld.

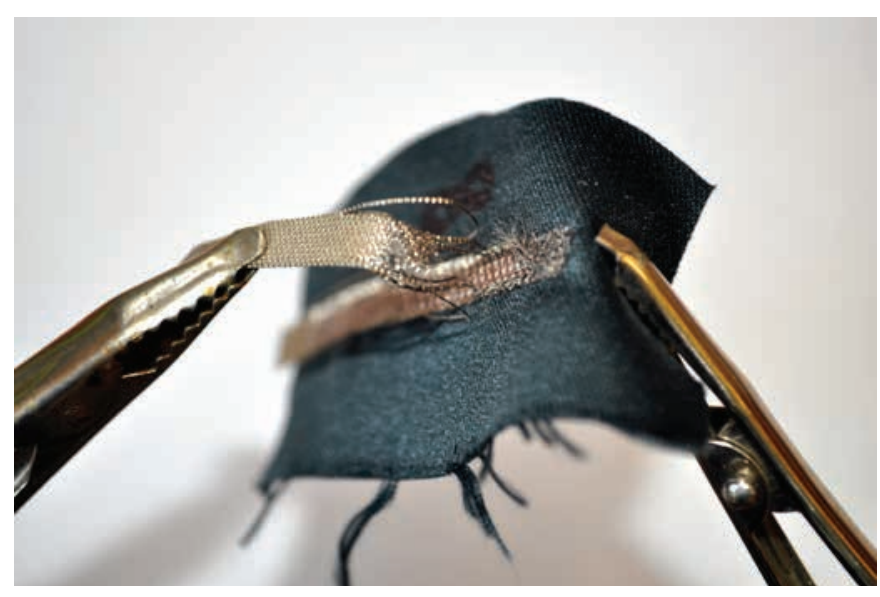

Figure 8. Broken fibres of the electroconductive path after bonding strength test.

of electroconductive paths (Figure 6). This often results in a complete loss of path conductivity. The tests also show that the paths very well welded to the ground are characterized by increased linear resistance (Figure 7).

To check the effect of welding power on changes in the linear resistance of the line non-parametric, $U$ Mann-Whitney test [22] 
was used. For this test, the zero hypothesis $\mathrm{HO}$ assumed no effect of the welding power on the linear resistance. Following the test results ( $p=0,000273)$, assuming the significance level at $\alpha=0.05$, welding power influences the change of the linear resistance.

Another disadvantage of direct welding of the electroconductive path to the substrate is hardly predictable parameters of the obtained line. This is caused, among others, by the destruction of the substrate by ultrasound at the welding points. These damages consist of melting the thread and changing the thickness of the substrate (Figure 9). These damages are particularly large at high ultrasound power needed for proper welding. Changes in substrate thickness have a significant impact on transmission properties, especially in TSL with paths located on both sides of the substrate (Figure 1).

Ultrasonic welding technology is also not appropriate for the construction of TSL with electroconductive paths located on both sides of the substrate which overlap as shown in Figure 10a. In this case, the probability of a short circuit between them is very high. In areas (4) (Figure 10a), short circuits may occur. This probability is particularly high in the case of high welding power, and thin textile materials used as the substrate of the line. The phenomenon of short circuits does not occur when the electroconductive paths (1) and (3) located on both sides of the substrate do not overlap as shown in Figure 10b.

The aforementioned observations lead to the conclusion that the realization of a properly functioning TSL made by direct welding of electroconductive paths to the substrate is practically not possible. This observation applies to both DC and high-

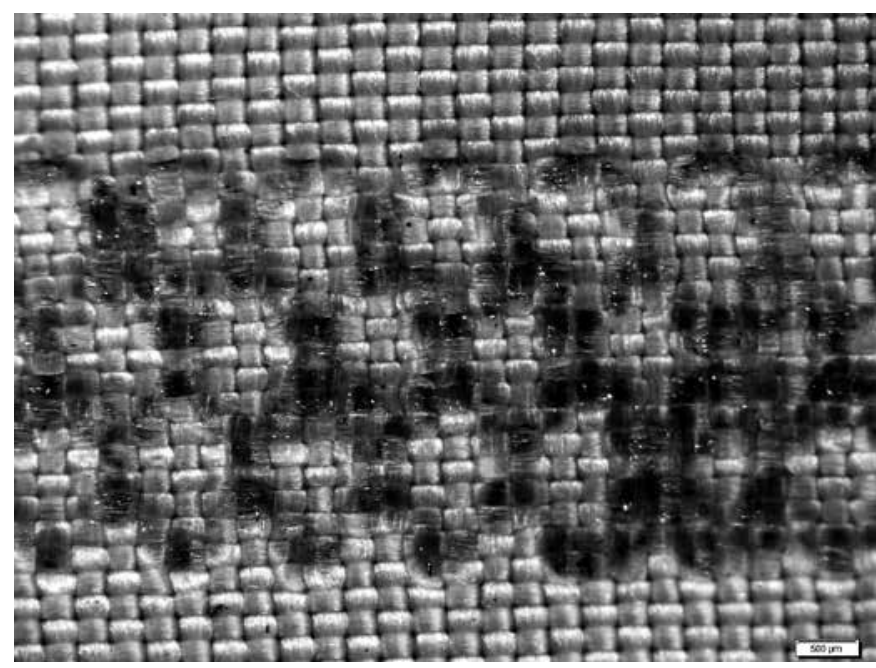

Figure 9. Damages of the textile substrate caused by ultrasonic welding (power - 60\%, speed - 0,5m/min, pressure - 4,0 Bar).

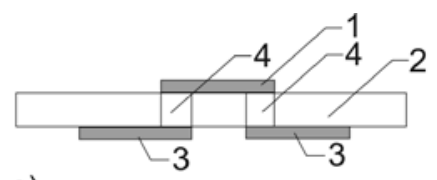

a)

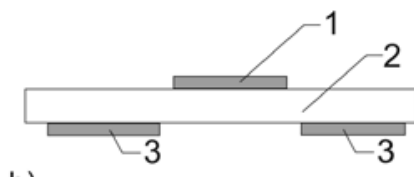

b)

Figure 10. TSL example with (a) overlapping signal paths and (b) nonoverlapping signal paths. frequency lines. Therefore, in the second part of the presented research, the TSL with additional covers (Figures 1 and 2) were investigated. In these lines, the electroconductive paths are attached to the substrate with additional textile covers. The realization of the line from Figure 1 with additional covers requires the proper welding order as shown in Figure 11.

The welding order, shown in Figure 11, ensures no damage to electroconductive paths caused by welding. The weld (1) (Figure 11) is made without any electroconductive path. Welds (2) are made without bottom, ground paths. It assures that during the entire process the electroconductive paths are not directly exposed to ultrasound. The main advantage of this TSL is that the linear resistance of electroconductive paths does not change during welding. The TSL from Figure 1 and coplanar TSL (Figure 2) were created using this method and all fabrics (Table 2) as a substrate.

Then, the measurements of the characteristic impedance and scattering parameters of the produced lines were carried out.

The characteristic impedance of the TSL from Figure 1 depends on the distance between the electroconductive ground paths. The smaller the distance between them, the smaller the characteristic impedance. Also, for coplanar TSL smaller distances between ground paths and signal path result in a lower characteristic impedance. Making TSLs with low impedances requires the use of a thin sonotrode. This will allow placing electroconductive paths in a short distance from each other.

The so-called impedance profile shows characteristic impedance at each point of the line. On the $x$-axis distance from the beginning of the line is shown. Obtained impedance profiles of the TSL and the coplanar TSL with covers (Figure 1) are shown in Figures 12 and 13, respectively.

The lines made are characterized by high unevenness of the characteristic impedance value along the line. This causes high reflections of the signal passed through the line (Figure 14). High signal reflections from the line are one of the reasons for the low level of the signal passing through the line. This is demonstrated by the large, negative values of the $s 21$ coefficient, as shown in Figure 15.

Significant dispersion of the characteristic impedance value over the length of the line is caused mainly by the uneven spacing between the signal paths. This is due to the unintended movement of the electroconductive paths during welding. In general, this is due to the difficult control of the mutual position

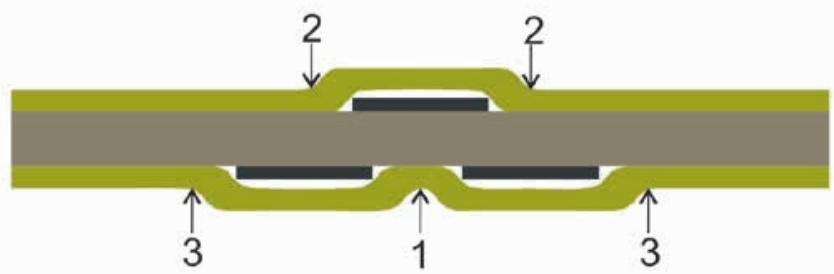

Figure 11. Welding order in constructed lines with additional covers. 


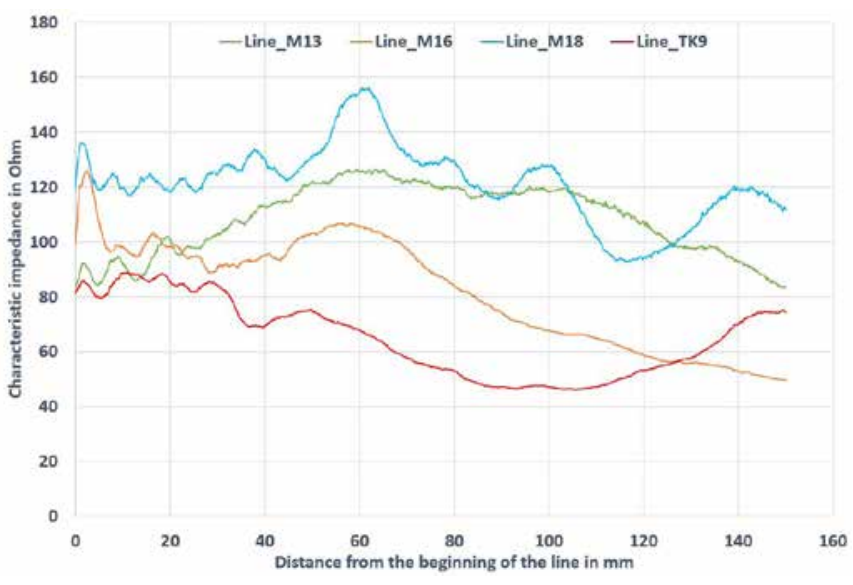

Figure 12. Impedance profiles of the TSL with additional covers.

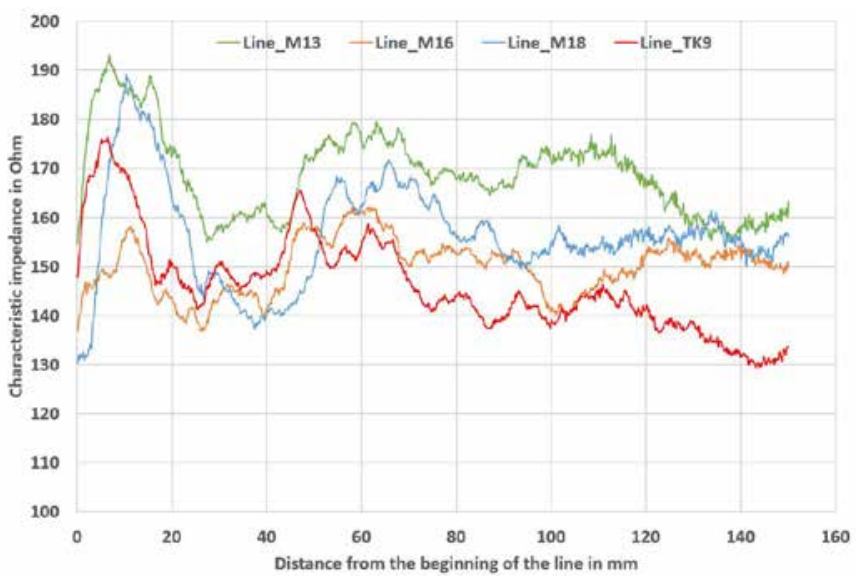

Figure 13. Impedance profiles of the coplanar TSL with covers.

of the electroconductive paths during welding. Another reason may be an uneven distance between electroconductive paths and the substrate. It causes the presence of air gaps between them.

Improvement of the transmission properties of the lines can be achieved by equipping the welding machine with elements ensuring a constant, even distance between the electroconductive paths during the welding process. Unfortunately, such elements are not commercially available, and therefore they would have to be designed and manufactured for the production of such lines. Another disadvantage of the welding method is the increased stiffness of the TSL in comparison with TSLs made using other technologies.

\section{Conclusions}

The presented research leads to the following conclusions:

- The welding method allows the construction of TSLs transmitting $D C$ and $A C$ signals with a frequency of up to several hundred $\mathrm{MHz}$. In these lines, additional textile layers (covers) should be used to fix the electroconductive paths to the substrate.

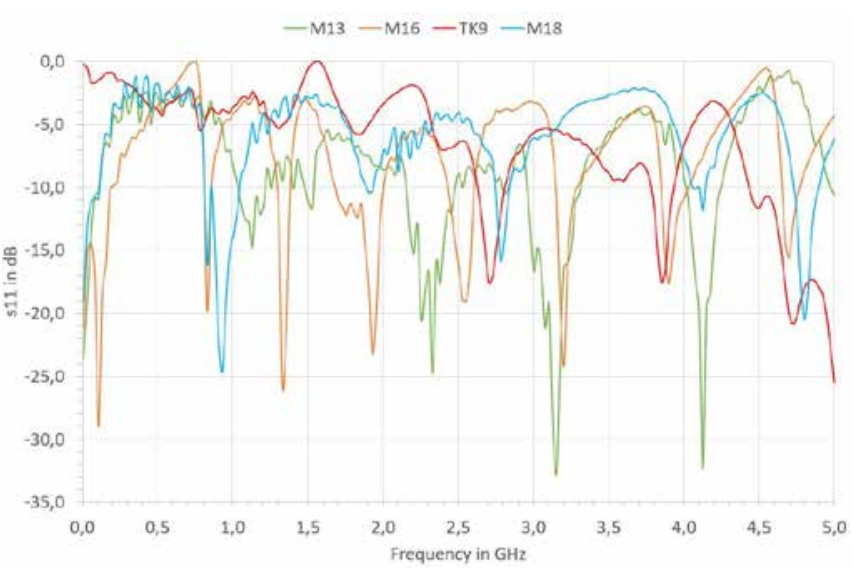

Figure 14. Parameter $\mathrm{s} 11$ as a measure of the reflection of the signal passing through the line from Figure 1

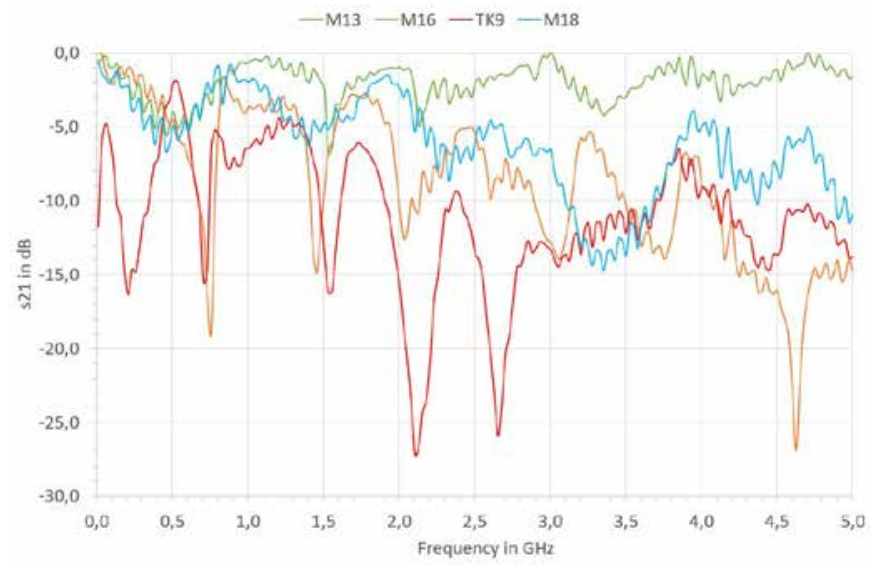

Figure 15. Parameter s21 as a measure of the signal passing through the line from Figure 1.

- Realization of a properly functioning TSL made by direct welding of electroconductive paths made from nickel-plated polyester to the fabric substrate is practically not possible (this conclusion applies to both DC and high-frequency lines). This is due to the destructive effects of ultrasound on the electroconductive paths of the line. These effects cause partial or complete loss of electrical conductivity of the electroconductive paths of the TSL.

- The lines obtained by welding are characterized by increased stiffness compared to lines made by other methods.

- Manual production of the TSL for high-frequency AC signals or high-speed digital signals using welding technology is very difficult. These types of lines require precise positioning of the electroconductive paths relative to each other. This precision requires the design and implementation of an automatic machine for keeping paths in strictly defined places during welding. This conflicts with one of the expected assumptions which is the simplicity of the method.

\section{Declaration of conflicting interests}

The authors declared no potential conflicts of interest with respect to the research, authorship, and/or publication of this article. 


\section{References}

[1] Lin, C.-C., Yang, C.-Y., Zhou, Z., Wu, S. (2018). Intelligent health monitoring system based on smart clothing. International Journal of Distributed Sensor Networks, 14(8), 1550147718794318.

[2] Pandian, P. S., Mohanavelu, K., Safeer, K. P., Kotresh, T. M., Shakunthala, D. T., et al. (2008). Smart vest: Wearable multi-parameter remote physiological monitoring system. Medical Engineering \& Physics, 30(4), 466-477.

[3] Paradiso, R., Loriga, G., Taccini, N. (2005). A wearable health care system based on knitted integrated sensors. IEEE Transactions on Information Technology in Biomedicine, 9(3), 337-344.

[4] Yang, C.-M., Peng, H.-Y., Zeng, W.-Y., Chen, C.-H., Lai, C.-S. (2016). Capacitive sweat sensor constructed by gui diatomaceous earth. Procedia Engineering, 168, 181-184.

[5] Hertleer, C., Tronquo, A., Rogier, H., Van Langenhove, L. (2008). The use of textile materials to design wearable microstrip patch antennas. Textile Research Journal, 78(8), 651-658.

[6] Indumathi, G., Bhavithra, J. (2017). Wearable textile antenna for indoor applications. In: 2017 International Conference on Inventive Communication and Computational Technologies (ICICCT), March 2017, pp. 30-34, doi: 10.1109/ICICCT.2017.7975221.

[7] Osman, M., Rahim, M., Azfar, M., Samsuri, N. A., Zubir, F., et al. (2011). Design, implementation and performance of ultra-wideband textile antenna. Progress In Electromagnetics Research B, 27, 307-325.

[8] Cottet, D., Grzyb, J., Kirstein, T., Troster, G. (2003). Electrical characterization of textile transmission lines. IEEE Transactions on Advanced Packaging, 26(2), 182190.

[9] Kim, Y., Member, S., Kim, H., Member, S., Yoo, H. (2010). $H$ : Electrical characterization of screen-printed circuits on the fabric. IEEE Transactions on Advanced Packaging, 33(1), 33-196.

[10] Locher, I., Tröster, G. (2007). Screen-printed textile transmission lines. Textile Research Journal, 77(11), 837842.

[11] Merritt, C. R., et al. (2005). Electrical characterization of printed coplanar waveguide transmission lines on specific nonwoven textile substrates. In: Materials Research Society Symposium Proceedings, Vol. 870, San Francisco, CA, USA, 2005, pp. 87-95.
[12] Leśnikowski, J. (2015). New kind of textile transmission line with an impedance of 50 Ohms. Fibres \& Textiles in Eastern Europe, 2(110), 51-54.

[13] Moradi, B., Fernández-García, R., Gil, I. (2018). E-textile embroidered metamaterial transmission line for signal propagation control. Materials (Basel, Switzerland), 11(6), 1-8.

[14] Post, E. R., Orth, M., Russo, P. R., Gershenfeld, N. (2000). E-broidery: Design and fabrication of textile-based computing. IBM Systems Journal, 39(3.4), 840-860.

[15] Nowak, I., Krucińska, I., Januszkiewicz, Ł. (2019). Metallic electroconductive transmission lines obtained on textile substrates by magnetron sputtering. Fibres \& Textiles in Eastern Europe, 27, 3(135), 51-57.

[16] Bahadir, S. K., Kalaoğlu, F., Jevšnik, S. (2015). The use of hot air welding technologies for manufacturing e-textile transmission lines. Fibers and Polymers, 16(6), 13841394.

[17] Atalay, O., Kalaoglu, F., Kursun Bahadir, S. (2019). Development of textile-based transmission lines using conductive yarns and ultrasonic welding technology for e-textile applications. Journal of Engineered Fibers and Fabrics, 14, 1558925019856603.

[18] EN 16812:2016. (2016). Textiles and textile products. Electrically conductive textiles. Determination of the linear electrical resistance of conductive tracks.

[19] Leśnikowski, J. (2020). Effect of temperature and humidity on the transmission properties of textile signal lines. The Journal of the Textile Institute, 111(4), 604-610.

[20] Hiebel, M. (2008). Fundamentals of vector network analysis. (1st ed.). Rohde \& Schwarz (Germany).

[21] Carlsson, J. (2019). Crosstalk on printed circuit boards. SP Swedish National Testing and Research Institute (Borås).

[22] Nachar, N. (2008). The Mann-Whitney U: A test for assessing whether two independent samples come from the same distribution. Tutorials in Quantitative Methods for Psychology, 4(1), 13-20.

[23] Stygiené, L., Varnaité-Žuravliova, S., Abraitienè, A., Padleckiené, I., Krauledas, S. (2020). Investigation of textile heating element in simulated wearing conditions. AUTEX Research Journal, 1, ahead-of-print, doi: 10.2478/ aut-2019-0080.

[24] Kurczewska, A., Leśnikowski, J. (2008). Variablethermoinsulation garments with a microprocessor temperature controller. International Journal of Occupational Safety and Ergonomics, 14(1), Web site: http://yadda. icm.edu.pl/baztech/element/bwmeta1.element.baztechOab0f3e7-39e2-4472-a2de-528c0d0d914f. [Accessed 6 March 2019]. 